\title{
Téoros
}

Revue de recherche en tourisme

\section{Tourisme et pays en développement : des problématiques fort complexes}

\section{Charles-Étienne Bélanger}

Volume 13, numéro 2, été 1994

Regards sur le tourisme dans les pays en développement

URI : https://id.erudit.org/iderudit/1077754ar

DOI : https://doi.org/10.7202/1077754ar

Aller au sommaire du numéro

Éditeur(s)

Université du Québec à Montréal

ISSN

0712-8657 (imprimé)

1923-2705 (numérique)

Découvrir la revue

Citer ce document

Bélanger, C.-É. (1994). Tourisme et pays en développement : des

problématiques fort complexes. Téoros, 13(2), 2-2.

https://doi.org/10.7202/1077754ar d'utilisation que vous pouvez consulter en ligne.

https://apropos.erudit.org/fr/usagers/politique-dutilisation/ 


\title{
Présentation \\ Tourisme et pays en développement : des problématiques fort complexes
}

\author{
Charles-Étienne Bélanger
}

L'idee que le tourisme pouvait apporter une contribution vitale à la croissance économique des pays en développement fut officiellement appuyee par les institutions internationales au début des années $1960^{\prime \prime}$. Depuis lors. I'idée a fait son chemin et de multiples expériences se sont concrétisées aux quatre coins de la planète. Les problématiques qui en ont découlé - qu'elles soient d'ordre politique, économique, socio-culturelouenvironnemental-illustrent bien les difficultés qu'il y a à vouloir cerner un phénomène aux dimensions complexes, voire même contradictoires.

Aujourd'hui, alors qu'on assiste de par le monde a trois révolutions simultanées et interdépendantes ${ }^{(2)}$, soit un certain triomphe de l'économie libérale. l'extensionetl'intérêt de plus en plus répandu pour les idées démocratiques et la révolution des techniques de l'information, force est de constater que des grandes régions du monde sont toujours dans des situations précaires. Sil'Asie del'Estajeteles bases de la croissance dans de nombreuxpays, sil'Amérique latine poursuit lentement son intégration économique avec ses voisins du Nord, que dire d'une Afrique quisemble de plus en plus en marge de l'économie mondiale avec ses problèmes démographiques, environnementaux, économiques et surtout politiques.

C'est a travers ces réalités complexes qu'il convient de porter certains regards critiques surle phénomène du tourisme dans les pays en développement. Le numéro proposé en offre quelques-uns. A travers des articles traitant de sujets généraux et quelques-uns illustrant la situation de certains pays, le lecteur sera en mesure d'apprécier les problèmes, enjeux et défis que posent le développement touristique dans plusieurs points du globe.

En guise dintroduction, Jean Stafford propose un article faisant l'état de la situation sur le plan conceptuel. Cing textes, davantage axés sur les aspects socio-politiques et économiques du tourisme dans les pays en développement, sont ensuite présentés. Georges Cazes aborde d'abord la question du tourisme international dans les relations Nord/ Sud sous l'angle des perspectives territoriales et géopolitiques. Puis, Linda K. Aichter expose les types de confiits politiques avant un impact sur le tourisme dans les nations en développement. Le soussigné propose ensuite un texte sur le röle des institutions financières internationales en retraçant I'intervention du Groupe de la Banque Mondiale. Gabriel Wackermann expose pour sa part la problématique du transport aérien dans les pays du Sud. Enfin, Regina G. Schluter brosse un portrait du role de l'État en matière de tourisme dans les pays d'Amérique du Sud.

La deuxième grande partie de ce numéro présente des problématiques liées à des pays où le tourisme s'est développé de façon importante, soit le Maroc, la Thailande, le Mexique et le Kenya. Mohamed Berriane traite d'abord de la complémentarité entre le tourisme national et le tourisme international au Maroc. Jean Michaud poursuit en posant un regard critique sur la mise en tourisme de l'exotisme tribal dans le Nord Thailandais. Jose Antonio Murillo pressente ensuite les grandes étapes du méga-projet touristique Isla Navidad au Mexique. Finalement. Paul Omondi explore les opportunités et les défis de l'écotourisme et du développement durable au Kenya.

En espérant que ce numéro puisse alimenter la réflexion sur le thème du tourisme dans les pays en développement et qu'il puisse contribuer, modestement, à une meilleure compréhension d'un phénomène aux problématiques difficiles. Souhaitons à tous une bonne lecture! $f$

\section{NOTES}

(1) C'est en 1963, lors de la Contérenceinternationale sur les voyages et le tourisme. que les Nations Unies appuient officiellement cette idée.

(2) Tel que formule par l'honorable Marcel Masse dans un discours prononce a l'oocasion du Colloque sur la carriere dans les organisations internationales, a Montréal, le 8 avril 1994 .

\section{En page couverture:}

Faca à face impromptu entre un camerounais de l'Afrique Sahélienne et un touriste québćcois revenant d'un safari-photo au Parc national de Wasa.

En surimpresssion :

- Femme Akha dans le nord de la Thailande dans la province de Chiang Rai. Pour les amateurs de coulcur locale, il n'y a pas que la réputation sulfureuse des nuits de Bangkok et le luxe des hôtels le long des plages de Pattaya et Phuket.

- En banlieue du Caire (9 km), sur le plateau de Giza, la pyramide de Kheops observée confortablement du Mena House Oberoï.

- Unepartie du front demer(avenidaAtlantica et plage Copacabana) de la baie fabuleuse de Rio de Janeiro. Absentes de la photo, les favelas accrochées au flane des collines environnantes où vivent plus d'un million d'habitants. 